\title{
Hepatotoxicity Due to Antituberculosis Therapy among Paediatric Patients Seen at the University of Ilorin Teaching Hospital, North Central Nigeria
}

\author{
Gobir Aishatu ${ }^{1,2^{*}}$, Ibraheem Rasheedah ${ }^{1,2}$, Johnson Wahab ${ }^{1,2}$, Muhammed \\ Sheni $^{1}$, Oladele Damilola ${ }^{1}$, Ojuola Adeniyi ${ }^{1}$
}

\footnotetext{
OPEN ACCESS

Citation: Gobir Aishatu , Ibraheem Rasheedah, Johnson Wahab, Muhammed Sheni, Oladele Damilola, Ojuola Adeniyi. . Hepatotoxicity Due to Antituberculosis Therapy among Paediatric Patients Seen at the University of Ilorin . Teaching Hospital, North Central Nigeria

Ethiop J Health Sci 2017;27(1):115. doi: http://dx.doi.org/10.4314/ejhs.v27i2.3

Received: November 23, 2016

Accepted: November 24, 2016

Published: March 1, 2017

Copyright: () 2015 Ashatu G.., et al.

This is an open access article distributed under the terms of the Creative Commons Attribution License, which permits unrestricted use, distribution, and reproduction in any medium, provided the original author and source are credited. Funding: -Nil

Competing Interests: The authors declare that this manuscript was approved by all authors in its form and that no competing interest exists.

Affiliation and Correspondence: ${ }^{1}$ Department of Paediatrics, University of Ilorin Teaching Hospital, Ilorin, Nigeria ${ }^{2}$ Department of Paediatrics, University of Ilorin, Nigeria

*Email: aishaakarim@yahoo.com; mopegobir@gmail.com
}

\begin{abstract}
BACKGROUND: The liver is vulnerable to injury from the first line anti-tuberculosis drugs. This may result in mortality, long term morbidity and reduced compliance to therapy. Nigeria recently introduced fixed drug combinations in the treatment of children amid concerns of hepatotoxicity. A 6-year-old boy was treated in our unit had fulminant hepatic failure two weeks after completing his anti-tuberculosis therapy. This prompted the unit to investigate hepatotoxicity due to anti-tuberculosis therapy among children. There is no data on the incidence of hepatotoxicity due to antituberculosis therapy among Nigerian children, and no uniform guide to monitoring of patients exists. The objective of this study was to investigate the incidence of hepatotoxicity among children receiving anti-tuberculosis therapy.

METHODS: A cross-sectional study was conducted among all 62 cases that completed treatment over a two year period. Liver Function Tests was done at baseline and 2 and 5 months of therapy. Elevation of Alanine aminotransferase and/or Aspartate aminotransferase above 3 times the reference values was considered an indication of hepatotoxicity.

RESULTS: A total of 62 patients aged 3 months -17 years were treated at our unit during the study period. Twenty-two (35.5\%) had elevated liver enzymes at baseline. Four (6.5\%) had elevation of alanine aminotransferase of 3 times the upper limit at 2 months, but at 5 months, tests were within normal limits in all patients. Hepatotoxicity defined as liver enzymes above 3 times upper limit was not documented among the 62 cases treated over the period.

CONCLUSION: Hepatotoxicity due to antituberculosis therapy is uncommon in children, hence repeated routine evaluation of liver function may not be necessary in all patients receiving anti-TB therapy.

KEYWORDS: Hepatotoxicity, anti-tuberculosis, children
\end{abstract}




\section{INTRODUCTION}

Tuberculosis (TB) remains a global public health threat, but Nigeria contributes disproportionately to the global disease burden and is the $3^{\text {rd }}$ high burden disease country with a prevalence of 326/100,000 in 2013 (1). Globally and in Nigeria, childhood TB accounts for about $6 \%$ of all new cases (2). In Nigeria, 5,463 cases were notified in 2014 mostly among those 5-14 years of age (3). TB is preventable and treatable in all age groups including in children. The treatment of all cases of $\mathrm{TB}$ is central to the care and control of TB in all settings. Antituberculosis drugs (ATD) became available in the $20^{\text {th }}$ century. The long duration of therapy has always been a major drawback in successful control of the disease (4). In addition, adverse drug reaction greatly influences adherence and compliance to antituberculosis therapy (ATT). Hepatotoxicity arising from the use of antituberculosis has remained a source of concern to medical practitioners (5). This is because the drugs-Isoniazid (H), Rifampicin (R) and Pyrazinamide ( $\mathrm{Z}$ )-usually implicated in hepatic toxicity are key components of ATT (5). The use of the fixed dose combination (FDC) in children was also accompanied with worries of probable increase in cases of hepatic toxicity $(5,6)$. Incidence of drug-induced hepatotoxicity in childhood is between $3 \%$ and $10 \%$, and severe hepatotoxicity is documented to be below $1 \%$ in children (5-8). The patients who have hepatotoxicity from ATT can have variable presentation from asymptomatic to acute liver failure and fulminant disease (5).There is no uniform recommendation for monitoring paediatric patients on ATT for hepatotoxicity $(6,7)$. Furthermore, there is no published study on ATT hepatotoxicity in paediatric patients in Nigeria. A 5-year-old male patient of our unit developed acute fulminant hepatitis shortly after completing a 6-month course of ATT. The patient was however never documented to have developed hepatotoxicity due to ATT, because patients were not routinely monitored during therapy. Thus, many unanswered questions arose. Therefore, over a two year period in our centre, clinical data of all children diagnosed with TB was prospectively collected using a study protocol. Data on socio- demographic distribution, clinical features, previous treatment for $\mathrm{TB}$, investigations and results, and treatment and adverse events was systematically collected. The aim of the study was to investigate the occurrence of hepatotoxicity among the patients during treatment. This study was conducted with the utmost ethical consideration as contained in the principles of the Helsinki Declaration. This paper reports our finding on hepatotoxicity among paediatric patients treated with ATT.

\section{MATERIALS AND METHODS}

Between January $1^{\text {st }}, 2014$ and December $31^{\text {st }}$, 2015 data was prospectively collected on sociodemographics (social class was assigned based on Oyedeji classification), clinical features, diagnosis, co-morbidities and nutritional status. All patients were screened for HIV. All patients in the two year period received the fixed-dose combination (FDC) and were treated following the treatment guidelines of the National Tuberculosis and Leprosy Control Programme (NTLCP) in Nigeria. Pulmonary TB and other extrapulmonary forms except meningitis and osteoarthicular disease received treatment for 6 months (2RHZ $+\mathrm{E}) / 4(\mathrm{RH})$. The continuation phase was prolonged to 10 months for meningitis and osteoarticular diseases. Drug dosages for FDC were $\mathrm{R} \quad 10-20 \mathrm{mg} / \mathrm{kg} ; \mathrm{H} \quad 7-15 \mathrm{mg} / \mathrm{kg} ; \mathrm{Z} \quad 30-$ $40 \mathrm{mg} / \mathrm{kg}$. Before the commencement of antituberculosis therapy (ATT), at 2 months and 5 months, patients had liver function tests (LFT) consisting of Alanine aminotransferase ALT, Aspartate aminotransferase (AST), Alkaline Phosphatase (ALK (P) and serum bilirubin. ALT and AST rise of more than 3 fold of the normal was considered significant. Patients with any elevation of liver enzymes at commencement of therapy had LFT done every 2 weeks. Rise of more than 3 times the normal was an exclusion criterion from the study. Progressive increase in LFT, jaundice and reduced appetite were considered significant signs of hepatotoxicity even when the LFT was not more than 3 times the normal. The management of hepatotoxicity was to follow the standard protocol of withdrawal of drugs, monitoring of LFTs and gradual

DOI: http://dx.doi.org/10.4314/ejhs.v27i2.3 
reintroduction of drugs (Rifampicin first). Other drug reactions were also documented but are not reported in this paper.

\section{RESULTS}

A total of 70 patients were diagnosed with TB from clinic and ward records, but only 62 patients aged 3 months to17 years and given ATT over the 2 year period had complete records that were analysed. The mean age (S.D) was $6.9( \pm 4.2)$ years. There were 29 males and 33 females with M:F ratio of $1: 1.1$; 0-4 years were 21 (33.9\%), 5-9 years were $25(40.3 \%)$, and those $\geq 10$ years were $16(25.8 \%)$. Table 1 shows the age, sex and social class distribution of the patients seen over the two year period. There were $4(6.5 \%)$ patients who were HIV positive and on anti-retroviral therapy (ART); a four and a half year old (1.6\%) haemoglobin SS patient with rheumatic heart disease was also diagnosed with TB; a 7 year old known controlled asthmatic also developed TB.

Table 1: Age, Sex and Social Class distribution of patients

\begin{tabular}{lc}
\hline Age years & $\mathbf{N}(\%)$ \\
$0-4$ & $21(33.9)$ \\
$5-9$ & $25(40.3)$ \\
$\geq 10$ & $16(25.8)$ \\
Total & $62(100.0)$ \\
Sex & \\
Male & $29(46.7)$ \\
Female & $33(53.3)$ \\
Total & $62(100.0)$ \\
Social Class & \\
Low & $40(64.5)$ \\
Middle & $16(25.8)$ \\
High & $6(9.7)$ \\
Total & $62(100.0)$ \\
\hline
\end{tabular}

The diagnosis was Pulmonary TB (PTB) in $36(58.1 \%)$, 11(17.7\%) had disseminated TB, $2(3.2 \%)$ patients presented with miliary $\mathrm{TB}$, $8(12.9 \%)$ patients had $\mathrm{TB}$ of the spine and $5(8.1 \%)$ were cases of TB adenitis (Table 2). Thirty-two (52.6\%) had normal nutritional status, $15(24.1 \%)$ were underweight, $12(19.4 \%)$ had

Table 2: Diagnosis among the study population marasmus, while $3(4.8 \%)$ had marasmickwashiorkor. A total of 36 patients were under 5 years of age, and $30(83.3 \%)$ had malnutrition with underweight occurring in $15(41.6 \%)$. The top 7 symptoms at presentation were cough, weight loss, fever, difficulty in breathing, production of sputum, back swelling and haemoptysis (Table 3).

$\begin{array}{ll}\text { Diagnosis } & \text { No(\%) } \\ \text { Pulmonary TB } & 36(58.1) \\ \text { Disseminated TB } & 11(17.7) \\ \text { Miliary TB } & 2(3.2) \\ \text { Spinal TB } & 8(12.9) \\ \text { TB adenitis } & 5(8.1) \\ \text { Total } & 62(100.0)\end{array}$

DOI: http://dx.doi.org/10.4314/ejhs.v27i2.3 
Table 3: Symptoms at presentation among cases

\begin{tabular}{lc}
\hline Symptom & No(\%) \\
Cough & $35(56.5)$ \\
Weight loss/failure to thrive & $26(41.9)$ \\
Fever & $23(37.1)$ \\
Difficulty in breathing & $11(17.7)$ \\
Production of sputum & $13(21.0)$ \\
Haemoptysis & $5(8.1)$ \\
Back swelling & $7(11.3)$ \\
Neck swelling & $4(6.5)$ \\
\hline
\end{tabular}

Three patients presented with fast breathing and night sweats; two with generalized lymphadenopathy and one with abdominal swelling.

LFT done before ATT was commenced showed derangement in liver enzymes in $22(35.5 \%)$, but all elevations were below 3 times the upper limit of normal $(\mathrm{N})$ from the reference laboratory (Table 4). None of the 22 patients showed increasing liver enzymes on further examination at
2 weeks after the commencement of ATT. At 2 months after the commencement of treatment, LFTs showed AST (0-33 IU/L) and ALT (1-19 $\mathrm{IU} / \mathrm{L})$ ranges below the baseline figures. The range of ALT (1-20 IU/L) and AST (5-30 IU/L) at 5 months is shown in Table 5.

Table 4: Liver function tests at baseline in the study population

\begin{tabular}{lllll}
\hline & Range (IU/L) & $\begin{array}{l}\text { No. }(\%) \text { with } \\
\text { elevated levels }\end{array}$ & $\begin{array}{l}\text { No.(\%) normal } \\
\text { levels }\end{array}$ & Total \\
\hline AST (0-15) & $6-45$ & $9(14.5)$ & $53(85.5)$ & 62 \\
ALT (0-20) & $0-27$ & $13(21.0)$ & $49(79.0)$ & 62 \\
ALP & $34-698$ & $42(67.7)$ & $20(32.3)$ & \\
Bilirubin & $<20-168$ & & & \\
\hline
\end{tabular}

N.B: Twenty -two (35.5\%) of all patients had elevated ALT and or AST

Table 5: Liver function tests at baseline, 2 and 5 months

\begin{tabular}{lllll}
\hline & $\begin{array}{l}\text { AST }(0-15 \text { IU/L) } \\
\text { range }\end{array}$ & $\begin{array}{l}\text { ALT }(0-20 ~ I U / L) \\
\text { range }\end{array}$ & $\begin{array}{l}\text { ALP(21->600) } \\
\text { range }\end{array}$ & $\begin{array}{l}\text { BILIRUBIN (0-2 } \mu m o l / L \\
\text { range }\end{array}$ \\
\hline Baseline & $6-45$ & $0-27$ & $34-698$ & $<20-168$ \\
2 month & $0-33$ & $1-19$ & $83-385$ & $<20$ \\
5 month & $5-30$ & $1-20$ & $101-476$ & $<20$ \\
\hline
\end{tabular}

\section{DISCUSSION}

The liver is vulnerable to injury from drugs and many other toxins because of its unique anatomy and physiology. The liver has many functionssecretory, synthetic, metabolic and detoxifying roles. In its metabolic roles, it transforms some drugs into toxins that can cause injury to hepatocytes. Different mechanisms for hepatotoxicity have been studied-cytochrome P450-dependent toxicity, bile-induced hepatocyte apoptosis, and mitochondrial dysfunction and peroxynitrite toxicity. However, it is generally thought that many mechanisms play out in ATT hepatotoxicity (9). Of utmost importance is the occurrence of ATT hepatotoxicity as it can affect compliance, outcome of management and result in death (10-12). The FDC were recently introduced

DOI: http://dx.doi.org/10.4314/ejhs.v27i2.3 
among children in Nigeria, but there is no clinical experience about its use and adverse effects related to the liver.

Tuberculosis as a disease can affect the liver, and although no patient in our study presented with jaundice, elevated liver enzymes at baseline was found in about one-third of the patients. AST, ALT singly or in combination were elevated in patients before ATT were started although below 3 times the upper limit as shown in table 4. The range of AST and ALT documented in the patients at 2 and 5 months of therapy was similar, and below the baseline levels. No patient had jaundice at presentation or during the course of treatment. This is important as jaundice is used as a clinical sign for referral of patients on ATT from lower level facilities to higher levels of care. The present finding supports the fact that drug induced hepatotoxicity in children receiving ATT is uncommon despite the frequent finding of elevated LFT at baseline, and it is consistent with the literature which shows that incidence of druginduced hepatotoxicity in childhood is between $3 \%$ and $10 \%$; severe hepatotoxicity is documented below $1 \%$ in children $(6-8,10,11)$. Therefore. with the current FDC at the dosages being used in Nigeria, the incidence of hepatotoxicity is uncommon. This finding is important as it will provide a basis on which to counsel patients for ATT. In addition, this can allay the anxiety among those who care for children with TB. While this may not be enough to make recommendations on monitoring hepatotoxicity in children, it will provide data for systemic reviews for future reference on monitoring.

The routine monitoring of LFT will increase the cost of TB treatment and may not be necessary. This is of utmost importance as the majority of patients affected are poor as shown by the social class of patients in this study. Furthermore, an additional test may create significant financial barrier to care. However, for safety reasons for liver injury may occur in children, it could be done when necessary. There are calls for early monitoring of LFT in adult patients to reduce cases of hepatotoxicity $(12,13)$. This cannot be said to be the same for paediatric patients.
Although it is not possible to make recommendations on monitoring of children on ATT based on this study, for now, it would appear safe to individualize care based on presentation and baseline LFT. We therefore conclude that hepatotoxicity to ATT is uncommon among children. This is true even with the use of the FDC and in spite of the high incidence of elevated liver enzymes at presentation in paediatric TB patients.

\section{REFERENCES}

1. World Health Organisation. Global TB report 2015. www.who.int/tb/publications/global_report/gt br15-annex02.pdf. accessed 25th June, 2016

2. World Health Organisation. Tuberculosis country

profiles.www.who.int/tb/country/data/profiles/ en/. Accessed $25^{\text {th }}$ June, 2016.

3. Federal Ministry of Health. National Tuberculosis, Leprosy and Buruli ulcer management and control guidelines, 2015.

4. Yew WW, Leung CC. Antituberculosis drugs and hepatotoxicity. Respirology 2006; 11(6):699-707.

5. Blumberg HM, Burman WJ, Chaisson RE, et al. American thoracic society, Centers for Disease Control and prevention and The Infectious Diseases Society of America: Treatment of tuberculosis. Am J Respir Crit Care Med 2003; 167:603-62.

6. Peter RD. Antituberculosis drug-induced hepatotoxicity in children. Pediatric Reports 2011; 3:e16:51-65.

7. Bhatia S, Tullu MS, Kannan S, et al. an unusual recurrence of antitubercular drug induced hepatotoxicity in a child. J Postgrad Med 2011; 57: 147-52.

8. Devrim I, Olukman O, Can D, et al. Risk factors for INH hepatotoxicity in children with latent TB and TB: differences from adults. Chest 2010; 137: 737-8.

9. Hartmit J, Gregory JG, Arthur IC, et al. mechanism of hepatotoxicity. Toxicological sciences 2002; 65:166-176.

10. Saukkonen JJ, Cohn DL, Jasmer RM, et al. Official statement of American Thoracic Society: Hepatotoxicity of antituberculosis

DOI: http://dx.doi.org/10.4314/ejhs.v27i2.3 
therapy. Am J Respir Crit Care Med 2006; 174: 935-52.

11. Ohkawa K, Hashiguchi $\mathrm{M}$, Ohno $\mathrm{K}$, et al. Risk factors for antituberculous chemotherapy induced hepatotoxicity in Japanese Paediatric patients. Clin Pharmacol ther 2002; 72:220-6.

12. Shu CC, Lee $\mathrm{CH}$, Lee $\mathrm{MC}$ et al. hepatotoxicity due to first line antituberculosos drugs: a five year experience in a Taiwan Medical centre. Int J Tuberc Lung Dis 2013; 17(7):934-9.

13. Lee CM, Lee SS, Lee JM, et al. Early monitoring for detection of antituberculosis drug-induced hepatotoxicity. Korean J Intern Med 2016; 31(1):65-72. 